\title{
Two Parts of Reflective abstraction: For New Problem Solving and Mathematical Concept
}

\author{
Risnina Wafiqoh ${ }^{1}$, Yaya Sukjaya Kusumah ${ }^{2}$, Dadang Juandi ${ }^{3}$ \\ \{risnina.wafiqoh@stkipmbb.ac.id ${ }^{1}$, yskususmah@upi.edu ${ }^{2}$, dadang.juandi@upi.edu ${ }^{3}$ \} \\ Universitas Pendidikan Indonesia ${ }^{1,2,3}$, STKIP Muhammadiyah Bangka Belitung ${ }^{1}$
}

\begin{abstract}
This research aimed to describe the reflective abstraction exhibited by each of part of reflective abstraction. The research question was about How is students" reflective abstraction in reflecting their prior knowledge into higher thought and reorganizing the new mathematical concept. We performed a qualitative research approach with a study case design as the research method. This study involved $3611^{\text {th }}$ grade students and 36 $12^{t h}$ grade students. The data was analyzed qualitatively by using hyperRESEARCH application. The first part of the students' reflective abstraction could be seen from how the students developed the concept of mathematical problem solving on the mathematical problem testing, while the second part of the reflective abstraction could be seen on the process of developing core concepts of mathematics learning.
\end{abstract}

Keywords: Reflective abstraction, Problem Solving, Mathematical Concept

\section{Introduction}

In learning mathematics, there are many abilities that must be possessed by students in learning mathematics, one of which is a reflective abstraction. The idea of reflective abstraction was first developed and expanded by Jean Piaget [1,2]. Reflective abstraction is part of the abstraction which is the best and most important abstraction compared to another abstraction $[3,4]$.

Reflective abstraction includes abilities that are very important because mathematical concepts will be known, formed, and produced by students through reflective abstraction [2]. The importance of reflective abstraction is evidenced by the cognitive abilities in which students are able to develop due to reflective abstraction [5,6]. In addition, concepts built from reflective abstraction will be used as a basis for building further concepts that relate to the concept [7]. Mathematical concepts are the main points in learning mathematics, students who understand mathematical concepts will have no difficulty in dealing with any situation in mathematics. Even when students are given the most difficult mathematical problems, they can solve these problems by understanding their mathematical concepts. Mathematical concepts will be formed, produced, and understood if students involve their reflective abstraction, this clearly proves that reflective abstraction is significant to support students understanding in learning mathematics.

According to Cifarelli [8] there are four levels of reflective abstraction, they are Recognition, at the first level, students are able to remember previous activities related to the situation they face; Representation, at this level, students can use the help of diagrams, tables, etc. in order to be able to help and facilitate students to solve the situation they face; Structural Abstraction, at this level, students are able to build new concepts based on the results of 
projecting and rearranging the concepts they created; structural Awareness, students are able to build new concepts without completing procedures completely and anticipate the concepts that they built.

Reflective abstraction is divided into two parts which are to estimate concepts that will be formed to be used in higher thinking by using concepts that are already known / previously owned, and reorganizing/reshaping a new mathematical concept by involving concepts owned by students $[2,4,6,9]$. The first reflective abstraction part is to form the concepts used in higher thinking that can be seen when students from a concept in solving mathematical problems. The second part of reflective abstraction can be seen when students form mathematical concepts that are at the core material of mathematics learning. Reflective abstraction is the ability to build mathematical concepts by connecting some interconnected concepts that are already owned by students. Building concepts on reflective abstraction can be in the form of new mathematical concepts recognized by students as well as mathematical concepts in order to solve mathematical problems faced by students.

Solving mathematical problems is a common activity and is considered as a basic component that is often faced by students for all levels of education [10-13]. When students are given a mathematical problem, the teacher can give students the freedom to solve the mathematical problem by using their own ways in order that they can encourage students to think independently and use different and open strategies [14]. With different strategies, students can develop concepts to solve this problem in order that students' reflective abstraction will be seen.

The reflective abstraction part of students that can be seen from the problem-solving process is one of the important things that must be developed by students because developing students' ability to solve mathematical problems is the main goal in learning mathematics [1517]. The main objective in mathematics according to others says that learning and teaching mathematics might have to make students able to solve problems in daily life and to become good problem solvers $[18,19,20]$. The ability of students in learning mathematics can develop if students are often involved in the problem-solving process to become good problem solvers [21]. A student who becomes a good problem solver will not only succeed in learning mathematics but will also succeed in overcoming problems in daily life [22]. Through problemsolving, mathematical operational knowledge and students' basic knowledge, the students will be easy to transfer them in order that learning will be more meaningful [11]. Mathematical problems are very important to be solved well by students. Students who cannot solve problems well will experience confusion, frustration and anxiety when they have difficulty in understanding and solving mathematical problems [23].

Another part of reflective abstraction is to rearrange/reshape a new mathematical concept by involving and connecting among concepts that have been previously owned. Building mathematical concepts is an important thing, students who can build their own concepts by involving the concepts they have before are students who have good reflective subtraction abilities. Students starting at an early age have knowledge of their respective concepts based on their daily experiences related to mathematics [24], therefore, there is no reason for students to say that they do not have enough concept stock to start building new concepts for them. In learning mathematics, students will more easily build and understand new concepts because of the interrelationship among concepts that already exist and are owned by students before [25], and of course, the mathematical concept should not have a problem in order that the next concept which is related will not also be a problem [26]. The mathematical concept is an important thing compared to the number of exercises, tests given by the teacher [27]. A student who understands mathematical concepts will certainly not experience difficulties in completing as many exercises 
and tests, but if the tests and exercises are given as much as possible, and students do not understand mathematical concepts, of course, the exercises and tests are not useful.

Reflective abstraction and the reflective abstraction section to solve problems and new mathematical concepts as described above are important things. Therefore, this article explains Two parts of reflective abstraction: for Problem Solving and New Math Concepts, With the formulated research question "How is students" reflective abstraction in reflecting their prior knowledge into higher thought and reorganizing the new mathematical concept.

\section{Method}

This research uses a qualitative approach with a case study research design. The research involves 36 students of class XI to see the reflective abstraction part, which is to rearrange/reshape a new mathematical concept by involving concepts owned by students. The subject of class XI was chosen because the formation of new mathematical concepts can only be seen in students who have not obtained material yet related to the new concepts they will build. Furthermore, 36 students of class XII is to see the reflective abstraction, which is to estimate the concept that will be formed to be used in higher thinking by using concepts that are already known / previously owned. The subject of class XII was chosen because students of class XII have studied a material that was chosen as the main material in forming mathematical problems in order to see the reflective abstraction part. The students of Class XI and XII are given a test twice. Test results are analyzed qualitatively with the help of the hyperREASEARCH program.

\section{Results and Discussion}

\subsection{Results}

Student results on the reflective abstraction section for mathematical problem solving. The reflective abstraction section "estimated the concepts that would be formed to be used in higher thinking" and was analyzed from mathematical problem solving by class XII students. In this section, the results of two students were taken in completing two tests. The results of students constructed concepts / estimated concepts in solving problems as follows:

Student results in solving problems on the first test.

Result of subject 2 in completing the first test problem No. 1 as can be shown in Figure 1. 


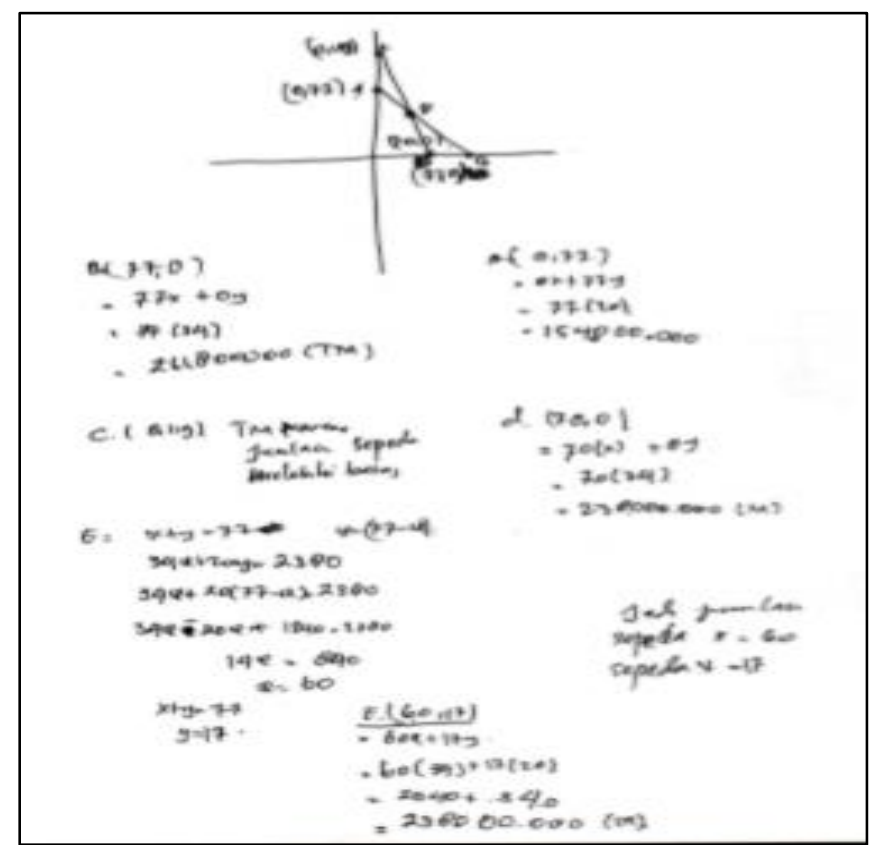

Fig. 1. Subject result 2 in solving problems on the first test, the problem No. 1.

In the picture above it can be seen from the results of subject 2. Subject 2 could separate the number of bicycles into variables in order that they could build mathematical models correctly. Subject 2 used the help of images to make it easier to solve the problem, but there was a mistake in determining the coordinates of the images used as results. Subject 2 made points $\mathrm{A}, \mathrm{BC}, \mathrm{D}$, and $\mathrm{E}$ as a result to get the number of bicycles (i) and type bikes (ii) that met the requirements according to subject 2 . The points that should be tested to get the number of bicycles (i) and (ii) where points A, D, and E. The number of bicycles (i) produced by subject 2 was 60 , and bicycles of type (ii) were 17 bicycles which were the right result. However, the concept developed by subject 2 to solve the problem was a wrong concept because it involved all the points as a test point to determine the results of the many types of bikes (i) and types (ii).

3.1.2 Student results in the reflective abstraction section for mathematical concepts

The reflective abstraction section "rearranged/reshaped a new mathematical concept by involving concepts owned by students" and was analyzed from how class XI students constructed new mathematical concepts for them by involving and linking previous concepts that they had. In this section, the results of two students were taken in completing two tests. The results of students building new mathematical concepts were as follows:

The results of subject 3 in constructing the concept of inequality of two variables are as can be shown in Figure 2. 

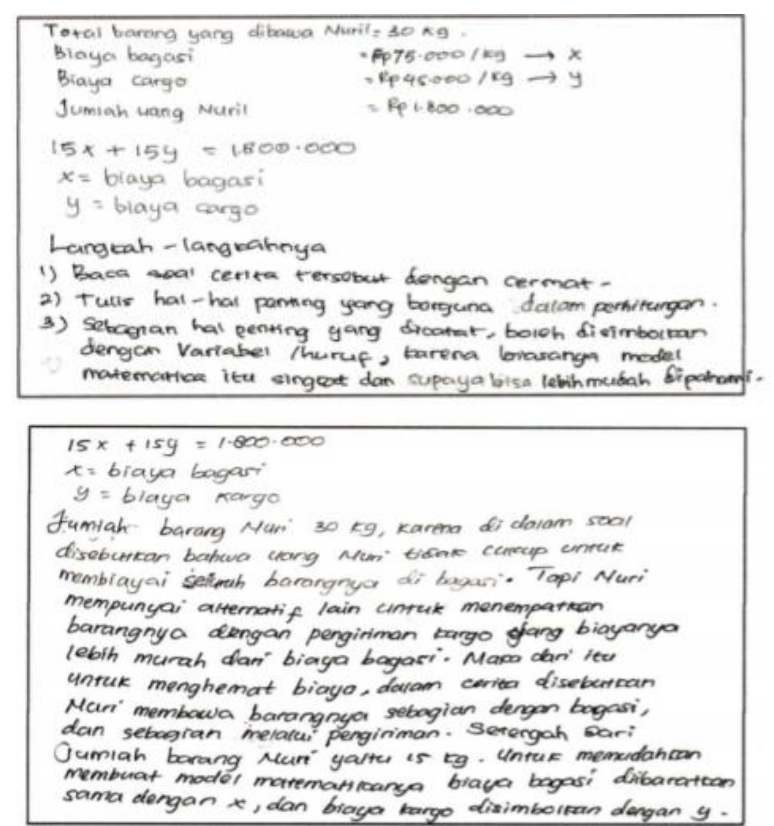

Fig. 2. Subject 3 results in constructing the concept of a two linear inequality system.

In the picture, it can be seen how subject 3 constructed the concept of linear inequality of two variables. The steps made to make the linear inequality of the two variables above were appropriate but not yet complete. because it was supposed to make a two-variable linear inequality based on the mathematical problems presented, it should change the important points that were still complete in everyday discussion into mathematical language by involving variables that had been made in such a way that they formed a linear inequality of the two variables. Subject 3 according to the steps he made, wrote down the important points, but when taking everyday language into variable form, subject 3 experienced an error. Subject 3 supposed that $\mathrm{x}$ is the cost of baggage, and $\mathrm{y}$ was the cost of the cargo. Supposedly in the form of a variable was something that was not yet known in order to make it easier to know its value. Baggage and cargo fees were already known in advance as written by subject 3 as shown above.

\subsection{Discussion}

In this discussion, we will discuss how the levels of abstraction produced by research subjects, which were viewed from the reflective abstraction section. "Reorganizing/reshaping a new mathematical concept by involving concepts owned by students and estimating the concepts that would be formed were used in higher thought by using concepts that were already known / previously owned. In the reflective extraction section, to build concepts on higher thinking was resulted from how students build concepts in solving mathematical problems while building mathematical concepts for students was analyzed from how students build concepts they had never known before.

It will be discussed first about the reflective abstraction section for solving mathematical problems. Subject 1 on problem-solving the first problem No.1 can build concepts to solve mathematical problems that were presented properly and complete procedures without making 
any mistakes. When viewed from the results, it can be said that in solving problem No.1 on the first test, subject 1 achieved level 3 reflective abstraction which was Structural Abstraction. In solving problem No.2, subject 1 used a graph as an aid, but because the inequality built by subject 1 had been mistaken, the graph made by subject 1 was a wrong graph and could not help subject 1 in constructing concepts to solve the problem. When viewed from these results, it can be said that at the completion of problem No. 2 on the first test, subject 1 reached level 2 which was Representation. In solving the problem on question No.1 of the second test, subject 1 did not give a reason why the chosen point was the intersection point between the two lines. Subject 1 developed concepts to solve problems correctly but did not provide complete procedures. therefore, it can be said that subject 1 in solving the problem No.1 second test had reached level 4, namely Structural Awareness. In solving problem No.2 on the second test, subject 1 used the help of a graph to determine the area of the cellphone. The endpoint in the HP area was tested by subject 1 to produce the least value. However, in developing the concept to solve the problem, subject 2 did not complete the procedure completely and chose as many as 4 superior rooms and 6 deluxe rooms which were the least expenditure. Because the concepts built to solve problems were imperfect and imprecise concepts, it can be said that subject 1 reached level 2, namely Representation.

Subject 2 in solving the first mathematical problem in the first test involved neurography to facilitate resolution. However, in developing concepts to solve these mathematical problems, subject 2 involved all the points in this picture that caused concept errors in solving problems in order that it could be seen that subject 2 reached level 2, namely Representation. In solving the first mathematical problem on the second test, subject 2 developed the concept with the help of the mathematical model that subject 2 had built before, to find the amount of small remaining car park space was by calculating the total parking area for small cars and buses and by reducing area for small car park space that had been used. There was a mistake in constructing the concept to solve the mathematical problem because what was produced was outside the remaining parking area for buses and small cars, and there was no amount of parking space left for small cars. The results concluded that subject 2 in solving the second mathematical problem on the first test reached level 2, namely Representation. Subject 2 in solving the first mathematical problem on the second test used the help of images and mathematical models to facilitate problem-solving. Subject 2 built a concept to solve mathematical problems by adding up income for one year and reducing the rented costs that were not rented so that income was generated for one year, but in developing the concept of solving the problem, subject 3 did not provide a reason why the maximum income received was by renting out rented type (i) as many as 4 rooms and rented type (ii) as many as 6 rooms. From the results of subject 2 , it could be concluded that subject 2 reached level 4, namely Structural Awareness. Subject 2 in solving the second mathematical problem on the second test used the help of a mathematical model but experienced errors in determining the sign, so the help using graphics also experienced errors. The concept built to solve this problem was to compare the results of the points obtained on the graph, and the smallest point was the final result. From these results, it can be concluded that subject 2 reached level 2, namely Representation.

The reflective abstraction section to build new mathematical concepts according to students was tested to students of class XI. When the subject was given a case to construct a concept of the two-variable inequality system, it would result in subject 3 to use help to change the everyday language into the form of a variable, but there was a misconception in converting it into the form of that variable. The concept of linear inequality system constructed by subject 3 was also an incomplete concept to be able to form a linear system of two variables that connects important points with variables that had been changed in order that everyday language could be 
changed into mathematical language and without any form of a linear inequality. two variables From these results it was concluded that subject 3 reached level 2, namely Representation. when given a case that allows subject 3 to construct the concept of a linear program, subject 3 would write that to determine something the maximum or minimum value was to provide several steps. Subject 3 used the help of a mathematical model, but the concept of a linear program developed by subject 3 did not use a complete procedure like the linear program procedure that we knew of. Subject 3 only involved concepts that he knew about mathematical models while other concepts related to linear programming such as using graphs and endpoints in order to get the maximum value and were not used by subject 3 as a step. Subject 3 uses steps to find the maximum or minimum value to get through possible trials. From these results, it can be concluded that subject 3 reached level 4, namely Structural Awareness.

Another subject involved in this research was to see how reflective abstraction in this section could build new concepts. according to them, it was subject 4 . when subject 4 was given a possible case, he would construct the concept of linear inequality of two variables. subject 4 wrote steps that helped to understand the problem and steps that could help remember important points related to the case. From these results, it can be concluded that subject 4 only reached level 1, namely Recognition. When subject 4 was given a case that allowed it to construct a linear program concept, it did not write the steps in solving the case but only wrote the important points of the case that did not show any concept related to the concept of a linear program in order that it could not be analyzed by the achievement level of the subject's reflective abstraction 4 in that case.

\section{Conclusion}

The reflective abstraction of students in projecting knowledge about existing concepts into higher forms of thinking in this study is seen from the results of students in solving mathematical problems. Students in solving mathematical problems reach the level of Representation, Structural Abstraction and Structural Awareness. While the reflective abstraction part about forming new mathematical concepts according to students by involving and connecting concepts that they have previously reached the level of Recognition, Representation, and Structural Awareness. At the level of Recognition in the reflective abstraction section for problem-solving, students are able to identify problems by involving knowledge of related concepts/lessons they have previously learned. The level of Recognition in the reflective abstraction section is to build new concepts in which students are able to identify the required concepts they already have. In level Representation of the reflective abstraction to solve problems, students are able to develop strategies to solve problems using assistance such as mathematical models, images, and graphics. In level Representation of the reflective abstraction section to build new concepts for students, students are in the process of building their new concepts by using help such as graphs and mathematical models. The level of Structural Abstraction in both parts of reflective abstraction can be characterized by the ability of students to develop mathematical concepts both to solve problems and concepts that they have just recognized, with very complete procedures without experiencing any errors and they are able to show the interrelationships and relationships between concepts. Level of structural Awareness on the part of abstraction is for problem-solving, and students are able to build concepts to solve problems without using related concepts in full without complete procedures and without making concept mistakes in order that problems can be resolved. Level Structural Awareness to 
build new concepts students are able to build new concepts without using complete procedures, and students can build concepts that are different from what is known procedurally and without making concept mistakes.

\section{References}

[1] Glasersfeld, E.V.: Abstraction, Re-Presentation, and Reflection: An Interpretation of Experience and Piaget's Approach. Epistemological Foundations of Mathematical Experience, 45-67. doi:10.1007/978-1-4612-3178-3_4. (1991)

[2] Dubinsky, E.: Constructive Aspects of Reflective Abstraction in Advanced Mathematics. Epistemological Foundations of Mathematical Experience, 160-202. doi:10.1007/978-1-4612-31783_9 (1991)

[3] Djasuli, M., Sa'dijah, C., Parta, I. N., \& Chandra, T. D.: Students' Reflective Abstraction in Solving Number. International Electronic Journal of Mathematics Education, 12(3), 621-632. Retrieved September 17, 2018, from https://www.iejme.com/download/students-reflective-abstraction-insolving-number-sequence-problems.pdf (2017)

[4] Cetin, I., \& Dubinsky, E.: Reflective Abstraction in Computational Thinking. The Journal of Mathematical Behavior, 47, 70-80. doi:10.1016/j.jmathb.2017.06.004 (2017)

[5] Dubinsky, E.: Reflective Abstraction in Advanced Mathematical Thinking (Vol. 11). Dordrecent: Springer. doi:10.1007/0-306-47203-1_7 (2002)

[6] Arnon, I., Cottrill, J., Dubinsky, E., Oktac, A., Feuntes, S. R., Trigueros, M., \& Weller, K.: From Piaget's Theory to APOS Theory: Reflective Abstraction in Learning Mathematics and the Historical Development of APOS Theory. Springer. doi:10.1007/978-1-4614-7966-6_2 (2013)

[7] Kara, M., Simon, A. M., \& Placa, N.: An Empirically-Based Trajectory for Fostering Abstraction of Equivalent-Fraction Concepts: A Study of The Learning Through Activity Research Program. The journal of Mathematical Behavior, 52, 134-150. doi:10.1016/j.jmathb.2018.03.008 (2018)

[8] Muniroh, A., Usodo, B., \& Subanti, S.: Algebraic Form Problem Solving Based on Student Abstraction Ability. Journal of Physics: Conference Series, 895. doi:10.1088/1742-6596/895/1/012038 (2017)

[9] Cooley, L.: Writing in Calculus and Reflective Abstraction. The Journal of Mathematical Behavior, 21(3), 255-282. doi:10.1016/S0732-3123(02)00129-3 (2002)

[10] Garcia, T., Boom, J., Kroesbergen, E. H., Nunez, J. C., \& Rodriguez, C.: Planning, Execution, and Revision in Mathematics Problem Solving: Does the order of the Phases Matter? Studies in Educational Evaluation, 61, 83-93. doi:10.1016/j.stueduc.2019.03.001 (2019)

[11] Caprioara, D.: Problem Solving - Purpose And Means Of Learning Mathematics In. Procedia Social and Behavioral Sciences, 191, 1859 - 1864. doi: 10.1016/j.sbspro.2015.04.332 (2015)

[12] Yee, S. P., \& Bostic, J. D.: Developing a Contextualization of Students' Mathematical Problem Solving. The Journal of Matehamtical Behavior, 36, 1-19. doi:10.1016/j.jmathb.2014.08.002 (2014)

[13] Doorman, M., Drijvers, P., Dekker, T., Panhuizen, M. D., Lange, J. D., \& Wijers, M.: Problem Solving as a Challenge for Mathematics Education in The Netherlands. ZDM Mathematics Education, 39(5-6), 405-418. doi:10.1007/s11858-007-0043-2 (2007)

[14] Intaros, P., Inparashita, M., \& Srisawadi, N.: Students' Problem Solving Strategies in Problem Solving-mathematics Classroom. Procedia - Social and Behavioral Sciences, 116, 4119-4123. doi:10.1016/j.sbspro.2014.01.901 (2014)

[15] Re, A. M., Lovero, F., Cornoldi, C., \& Passolunghi, M. C.: Difficulties of Children with ADHD Symptoms in Solving Mathematical Problems when Information Must be Updated. Research in Developmental Disabilities, 59, 186 - 193. doi:10.1016/j.ridd.2016.09.001 (2016)

[16] Lina, W., Ling, C., \& Cui, K.: SET: A Conceptual Framework for Designing Scaffolds in Support of Mathematics Problem Solving in One-to-One Learning Environment. International Conference on Information and Management Engineering, 234, 59-65. doi:10.1007/978-3-642-24091-1_9(2011) 
[17] Bazzini, L., \& Sabena, C.: Participation in Mathematics Problem-Solving Through Gestures and Narration. Educational Paths to Mathematics, 213-223. doi:10.1007/978-3-319-15410-7_13 (2015)

[18] Phonapichat, P., Wongwanich, S., \& Sujiva, S.: An Analysis of Elementary School Students' Difficulties in Mathematical Problem Solving. Procedia - Social and Behavioral Science, 116, 3169 3174. doi:10.1016/j.sbspro.2014.01.728 (2014)

[19] Davis, J. D., \& Seiwell, A. L.: Teachers' Perceptions of the Official Curriculum: Problem Solving and Rigor. International Journal of Educational Research, 93, 91-100. doi:10.1016/j.ijer.2018.10.002 (2019)

[20] Cai, J., \& Nie, B.: Problem solving in Chinese mathematics education: research and practice. ZDM Mathematics Education, 39(5-6), 459-473. doi:10.1007/s11858-007-0042-3 (2007)

[21] Masingila, J. O., Olanoff, D., \& Kimani, P. M.: Mathematical Knowledge for Teaching Teachers: Knowledge Used and Developed by Mathematics Teacher Educators in Learning to Teach via Problem Solving. Journal of Mathematics Teacher Education, 21(5), 21. doi:10.1007/s10857-017-9389-8 (2018)

[22] Yavuz, G., \& Hatice, N. E.: The Analysis of Pre-service Teachers' Beliefs about Mathematical Problem Solving. Procedia - Social and Behavioral Science, 174, 2687 - 2692. doi:10.1016/j.sbspro.2015.01.953 (2015)

[23] Leo, I. D., Muis, K. R., Singh, C. A., \& Psaradellis, C.: Curiosity... Confusion? Frustration! The role and Sequencing of Emotions During Mathematics Problem Solving. Contemporary Educational Psychology, 58. doi:10.1016/j.cedpsych.2019.03.001 (2019)

[24] Vitova, J., \& Balcarova, J.: Mathematical Concepts in Czech Pre-schoolers. Procedia - Social and Behavioral Science, 171, 713 - 716. doi:10.1016/j.sbspro.2015.01.182 (2015)

[25] Waiyakoon, S., \& Koraneekij, P.: Development of an Instructional Learning Object Design Model for Tablets Using Game-based Learning with Scaffolding to Enhance Mathematical Concepts for Mathematic Learning Disability Students. Procedia - Social and Behavioral Science, 174, 1489 - 1496. doi:10.1016/j.sbspro.2015.01.779 (2015)

[26] Dundar, S., \& Soylu, Y.: Perception Levels of the Students, Who have Qualified for University Admission, in Mathematical Concepts. Procedia - Social and Behavioral Science, 15, 3299 - 3303. doi:10.1016/j.sbspro.2011.04.289 (2011)

[27] Capriora, D.: Learning Focused on the Formation and Operation of the Mathematical Concepts Premise for Mathematical Skill in Middle School. Procedia - Social and Behavioral Science, 116, 3354 - 3358. doi:10.1016/j.sbspro.2014.01.763 (2014) 